\title{
Television-induced formed visual hallucinations and cerebral diplopia
}

\author{
AVINOAM B. SAFRAN, LANNING B. KLINE, JOEL S. GLASER, AND \\ ROBERT B. DAROFF
}

From the Bascom Palmer Eye Institute, Department of Ophthalmology, University of Miami, School of Medicine, Miami, Florida, USA

SUMMARY A 65-year-old man with ischaemic encephalomalacia following surgery for an aortic arch aneurysm experienced episodes of stereotyped formed visual hallucinations uniquely provoked by television viewing. In addition he noted vertical diplopia of cerebral origin. These symptoms are discussed in the light of what is known about visual hallucinations, television-induced epilepsy, and cerebral polyopia.

The occurrence of visual hallucinations induced by television viewing is extremely rare. ${ }^{1}$ This phenomenon was reported by a patient following an ischaemic encephalopathy. His visual experience seems unique in that the hallucinations were exclusively provoked by watching television. In addition diplopia of apparent cerebral origin was described.

\section{Case report}

A 65-year-old right-handed male with hypertensive cardiovascular disease underwent repair of an aortic arch aneurysm in October 1976. During the operation periods of hypotension occurred. In the recovery room before he regained consciousness 3 focal motor seizures involving the left arm and leg were observed. By the second postoperative day the patient responded to painful stimuli with extremity withdrawal and had intact oculocephalic responses and briskly reactive pupils. Deep tendon reflexes were brisk and plantar responses were extensor bilaterally. Over the next 2 to 3 weeks there was progressive improvement, though the patient had mild aphasia and lapses of memory. These postoperative neurological complications were thought to be sequelae of hypotensive periods or arterial embolism experienced during surgery.

One month after surgery the patient began experiencing formed visual hallucinations precipitated only by watching television (TV), which he did many

Correspondence to Dr A. B. Safran, Clinique d'Ophtalmologie, Hôpital cantonal universitaire, Geneva, Switzerland. hours a day. The hallucinations never occurred spontaneously or during other visual tasks. They began from several seconds to 30 minutes after he began watching TV and lasted for 10 seconds to 15 minutes. He could terminate the hallucinations in 5 to 10 seconds by looking away from the TV screen. The hallucinations were never precipitated by changing the channel or by instability of the television image.

There were 3 types of hallucinations. The commonest occurred approximately 12 times per day and consisted of large blocks of exceedingly clear letters and numerals. This image appeared in the centre of the field and moved slowly towards the right. A second hallucination consisted of the appearance of 'young girls' dressed in 'grey suits' marching out of step so as to produce a 'jiggling' or 'waving' sensation. This group always entered from the right lower portion of the visual field and moved towards the centre before disappearing. The third hallucination consisted of young boys, also marching 'out of step', moving from the centre of visual field to the right. These latter 2 perceptions occurred 3 to 4 times each day. During all 3 forms the patient was aware that he could 'still see through the images' as they moved in the visual field; they were always colourless, varying only in shades of grey.

When reading, the patient was initially aware of letters 'running together'. This was followed by a momentary disappearance of letters in the right paracentral visual field. These phenomena lasted a few seconds and were followed by the appearance of vertical separation of words just to the right of 


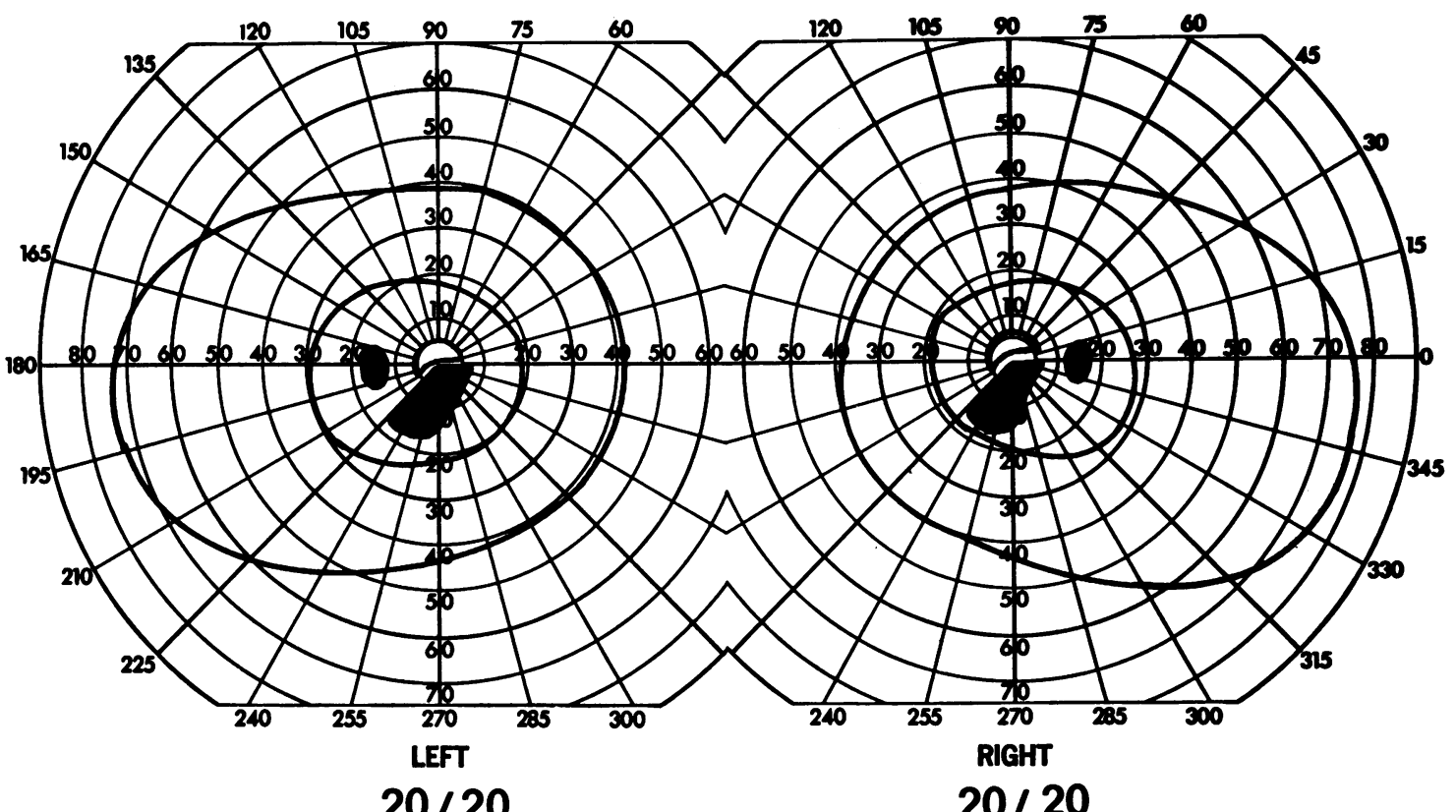

Fig. 1 Goldmann visual fields (I-1e, I-2e, I-4e isoptres). Note congruous paracentral bilateral homonymous scotomas.

fixation. The vertical diplopia persisted while viewing with either eye.

Examination at the Bascom Palmer Eye Institute 13 months after the onset of symptoms revealed visual acuity of 20/20 in each eye. Pupillary reactions, ocular motility, optokinetic nystagmus, slit-lamp examination, and fundi were within normal limits. When near vision was tested, the symptom of diplopia as noted above was described by the patient. Visual field examination disclosed a congruous bilateral homony- mous inferior paracentral scotoma (Fig. 1). During field examination the scotoma subjectively appeared and disappeared every 2 to 3 minutes.

On neurological examination the patient was alert and orientated. He was found to have a constructional apraxia, a total right hemihypalgesia, a mild quadraparesis, bilateral extensor plantar responses, brisk deep tendon reflexes, impaired bilateral rapid alternating movements, a broad-based gait, and truncal ataxia. A computerised tomographic (CT) scan (Fig.
Fig. 2 Computerised tomographic scan. Left: Mildly enlarged ventricular system with bilateral occipital lobe (open arrows) and left temporal lobe (black arrow) infarctions. Right: Right frontal defect (black arrow) noted in lower section.
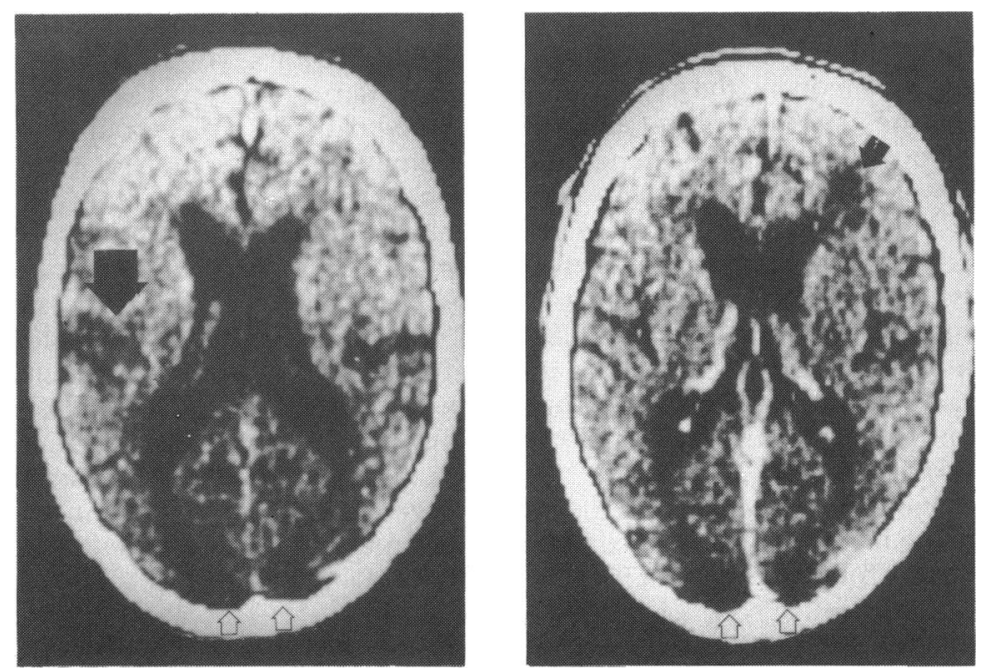
2) showed mild enlargement of the ventricular system and low-density defects in both occipital lobes which did not enhance after intravenous contrast injection. Radiolucent lesions were also noted in the left temporal and right frontal regions.

Because the patient was on warfarin (Coumadin) phenytoin therapy was deferred. The visual hallucinations spontaneously resolved in January 1977, having lasted for 13 months; the diplopia persisted. At that time an electroencephalogram with photostimulation was entirely normal. Three months later the patient died after an intracerebral haemorrhage shown by CT scan. A necropsy was not performed.

\section{Discussion}

The 2 major symptoms of our patient, televisioninduced formed visual hallucinations and nonocular diplopia, will be discussed separately.

\section{VISUAL HALLUCINATIONS}

In pioneering cortical stimulation experiments in awake subjects Penfield and associates ${ }^{23}$ found that stimulation of only the temporal lobes evoked formed (complex) visual hallucinations, whereas occipital cortex stimulation evoked unformed (primitive) sensations. These studies were supported by similar evocations of formed visual hallucinations with subcortical stimulation of the temporal lobes ${ }^{4}$ and led to the clinically useful inference that spontaneous complex visual hallucinations reflect temporal lobe dysfunction. Reports of formed visual hallucinations in alert patients with anterior visual pathway disease ${ }^{5}$ prompted $\operatorname{Cogan}^{6}$ to reconsider the localising significance of visual hallucinations. In the absence of a primary visual disturbance formed visual hallucinations probably are specific for temporal lobe disease. However, patients with a variety of visual defects due to anterior or posterior visual pathway lesions may also have complex hallucinations, presumably as a 'release' phenomenon, and these have no localising value. Furthermore, visual defects have been reported to precipitate formed visual hallucinations in psychiatric patients, and in some cases the hallucinations were restricted to the scotomatous area of the visual field. ${ }^{7}$

Our patient's particular type of formed visual hallucinations exclusively provoked by television viewing might be clarified from a brief review of the salient literature.

'Peduncular hallucinosis' was described by Lhermitte $^{8}$ in patients with midbrain lesions. Occurring only during sleepy states, these sensations consisted of brightly coloured geometric forms moving in a kaleidoscopic fashion or human figures, sometimes miniaturised. ${ }^{8-10}$ The generally accepted descriptions of peduncular hallucinosis differ from the experiences of our patient, although both types are recognised as 'unreal' and are not frightening to the patient.

In studying a group of patients with thalamic lesions De Morsier ${ }^{11}$ described formed visual hallucinations somewhat similar to those of our patient, although they occurred spontaneously without visual field defects. One patient described black-and-white soldiers arising from graves and marching from the periphery toward the centre of the field. There were also coloured flags, trumpets, and golden uniforms; immediately prior to resolution of the hallucination a number 17 was seen.

Forster ${ }^{12}$ reported 2 patients with occipital lobe injury who had formed kinetic hallucinations. One patient with a left homonymous inferior quadrantanopsia had visual hallucinations which began as the appearance of stars, bright points, and coloured clouds. Black people were seen in the left inferior quadrant of the visual field moving toward the centre and disappearing. The patient then experienced a complete left homonymous hemianopia and at times grand mal seizures. In this patient cortical stimulation of area 19 produced only unformed visual hallucinations. The second patient was said to be free of a visual field defect but described various hallucinations including light flashes and streaks, animals, and people, all beginning toward the right and moving to the centre. Occasionally these visual phenomena were followed by a sensation of falling to the right, vertigo, or by a major motor seizure. Cortical stimulation of area 19 in this patient precipitated formed visual hallucinations similar to those experienced spontaneously.

Lance ${ }^{1}$ reported 13 patients with homonymous visual field defects who experienced formed visual hallucinations in the defective hemianopic fields. Nine of these experienced stereotyped kinetic hallucinations of objects, people, and animals somewhat similar to those experienced by our patient. For example, a 62-year-old woman who sustained a right occipital lobe infarction secondary to vertebrobasilar insufficiency described a 'life-sized stream of people coming towards her from the left side.' In these 9 patients, examined by isotopic brain scanning and angiography, the lesions were considered to be parieto-occipital in location.

Visual hallucinations have been interpreted as either irritative (epileptic) or 'release' phenomenon. An epileptic aetiology is supported by Forster's observation ${ }^{12}$ that stereotyped formed kinetic visual hallucinations may occur as an isolated event or may be followed by a motor seizure; direct cortical stimulation may provoke a typical hallucinatory episode in such patients. Although Lance' ${ }^{1}$ concluded that the 
visual hallucinations of patients with hemianopias were of irritative origin, no conclusive evidence was presented. $\operatorname{Cogan}^{6}$ regarded episodic stereotyped hallucinations as probably irritative, as distinct from the continuous variable hallucinations which he felt represented 'release' phenomena.

In 1952 Livingston ${ }^{13}$ first reported TV-induced epilepsy. Subsequently, TV viewing has been reported to induce various types of seizures, including partial, Jacksonian, psychomotor, grand mal, ${ }^{14}$ and petit mal. ${ }^{15}$ Although patients of all ages may be affected, the majority of cases occur in children aged 6 to 14 years. ${ }^{16}$ Patients with previously known epilepsy or with no history of neurological disease are involved. ${ }^{141718}$ Seizures have been precipitated by a defective TV image with loss of vertical hold, by changing channel, ${ }^{14}$ 16-19 $^{-19}$ or during viewing of a normal functioning TV screen. ${ }^{15}$ Gastaut et al. ${ }^{14}$ recorded abnormal electroencephalogram (EEG) activity in 24 of 35 patients with TV-induced epilepsy. Others have reported abnormal EEG recordings by intermittent photostimulation,,$^{18}$ by interference with horizontal or vertical hold,$^{20}$ or even during viewing of a stable TV screen. ${ }^{21}$ Recently patients with TVinduced epilepsy were found to develop abnormal EEG recordings after viewing horizontal and vertical lines, both stationary and vibrated. This finding of pattern sensitivity may be a contributing factor in TV induced seizures. ${ }^{22}$

The occurrence of formed visual hallucinations induced by TV viewing is extremely rare. One patient of Lance ${ }^{1}$ who had a presumed right occipital infarction began to experience formed visual hallucinations 10 days after the acute event. The patient described a spontaneous appearance of 'a pair of elderly human hands, a tricycle, bicycle, pieces of honeycomb, pineapple, water running down the side of a glass, numbers or letters.' On a few occasions she saw the Union Jack and once a group of 'pink pigs.' At times while she was watching TV a piece of timber or the branch of a tree emerged from the screen and moved towards her, always stopping 2 to 3 feet (60-90 $\mathrm{cm}$ ) away. Our patient seems to be unique in that the formed visual hallucinations were induced only by watching television.

CEREBRAL DIPLOPIA OR POLYOPIA

Monocular diplopia or polyopia are extremely rare symptoms of central nervous system disease. Most commonly they are caused by optical aberrations of the eye ${ }^{23}$ or by strabismus. ${ }^{24}$ For the first time in the English-language literature Bender ${ }^{25}$ reported cerebral polyopia in 4 individuals. Subsequently 2 patients were reported by Kinsbourne and Warrington, ${ }^{26}$ and Meadows $^{27}$ reported a single case. Polyopia of cerebral origin varies from case to case.
Of Bender's 4 patients one described a partial second image to the left of the real object with a constant distance between the 2 ; the second patient noted a gap in the central portion of the object being observed; the third patient noted quadruple vision with 2 parallel pairs of images one above the other; and the fourth reported a complex form of variable polyopia, as for example a circle might be seen as 2 overlapping circles of equal size at one time and as 2 concentric circles, one within the other, at another time. Kinsbourne and Warrington's first patient reported reduplication of images with the faulty image so real he often reached for it; the second patient noted that when glancing at objects the image would 'suddenly multiply. ${ }^{26}$ Meadows's case had monocular diplopia while looking at newsprint or when focusing on small distant objects; he reported an overlapping image which over a period of about 2 seconds drifted up to the left, becoming less distinct and finally disappearing. In addition, he noted an occasional defect in his visual field just to the left of fixation, which persisted after the diplopia resolved and caused particular difficulty with reading. ${ }^{27}$

Emphasis should be given to the similarities of Meadows's case with the one reported here. In both (1) diplopia developed within seconds of fixation or reading, (2) congruous inferior homonymous paracentral scotomas lay within $20^{\circ}$ of fixation, and (3) these scotomas tended to disappear and reappear. Meadows attributed the clinical findings of his patient to an infarction at the tip and outer surface of the right occipital lobe. In our patient a lesion in a similar location but in both occipital lobes seems likely, given the results of visual field testing and CT scanning.

The mechanism of cerebral diplopia and polyopia is unknown. Bender ${ }^{25}$ postulated an instability of fixation due to occipital lobe disease. He speculated that fixation instability would lead to repeated ocular excursions at a rapid rate with consequent stimulation of retinal areas, or competing 'maculae.' In turn this would lead to transmission of conflicting visual information. Other evidence suggesting a role for the occipital lobe in the pathogenesis of cerebral diplopia or polyopia come from the work of Brindley and Lewin. ${ }^{28}$ In electrical individual stimulation of particular sites in the visual cortex a patient blind from glaucoma reported seeing 2, 3, or multiple points of light. Final elements of interest are the observations of Hubel and Wiesel. ${ }^{29}$ With binocular stimulations they have reported the existence of cells in the visual cortex which respond maximally to stimulation of noncorresponding retinal points. Thus there is evidence that structures exist in the occipital lobe which are functionally connected to different points in the visual field. 


\section{References}

1 Lance JW. Simple formed hallucinations confined to the area of a specific visual field defect. Brain 1976; 99: 719-20.

2 Penfield W, Rasmussen T. The Cerebral Cortex of Man: a Clinical Study of Localisation of Function. New York: Macmillan, 1950.

3 Penfield W. Perot $P$. The brain's record of auditory and visual experience. Brain 1963; 86: 595-696.

4 Horowitz MJ, Adams JE, Rutkin BB. Visual imagery on brain stimulation. Arch Gen Psychiatry 1968; 19: 469-86.

5 Weinberger LM, Grant FC. Visual hallucinations and their neuro-optical correlates. Arch Ophthalmol 1940; 23: 166-99.

6 Cogan DG. Neurology of the visual system. Springfield: Thomas. 1966: 270.

7 Burgermeister JJ.Tissot R. De Ajuriaguerra J. Les hallucinations visuelles des ophtalmopathes. Neuropsychologia 1968; 3: 9-16.

8 Lhermitte J. Syndrome de la calotte du pédoncule cérébral. Les troubles psychosensoriels dans les lésions du mésencéphale. $R e v$ Neurol (Paris) 1922; 29: 1359-65.

9 Lhermitte J, Bineau R. Les hallucinations visuelles consécutives aux lésions pédonculaires en foyer. Rev Neurol (Paris) 1937; 68: 827-31.

10 Rozanski J. Peduncular hallucinosis following vertebral angiography. Neurology 1952; 2: 341-9.

11 De Morsier G. Les hallucinations. Rev Otoneuroophtalmol 1938; 16: $244-352$.

12 Forster O. (1928). Quoted by De Morsier."

13 Livingston S. Comments on a study of light-induced epilepsy in children. Am J Dis Child 1952; 83: 409-10.

14 Gastaut H, Regis H, Bostem F, Beaussart M. Etude électroencéphalographique de 35 sujets ayant présenté des crises au cours d'un spectacle télévisé. Rev Neurol (Paris) 1960; 102: 533-4.
15 Pantelakis SN, Bower BD. Jones HD. (1962). Convulsions and television viewing. Br Med J 1962; ii: 633-8.

16 Charlton MH, Hoefer PFA. Television and epilepsy. Arch Neurol 1961; ii: 239-47.

17 Richter HR. Télévision et épilepsie. Rev Neurol (Paris) 1960; 103: 283-6.

18 Mawdsley C. Epilepsy and television. Lancet 1961; i: 190-1.

19 Fischer-Williams S. Epilepsy and television. Lancet 1961; i: $394-5$.

20 Andermann F. Self-induced television epilepsy. Epilepsia 1971; 12: $269-75$

21 Binnie CD, Darby CE, Hindley AT. Electroencephalographic changes in epileptics while viewing television. Br Med J 1973: iv: 378-84.

22 Stefansson SB, Darby CE, Wilkins AJ. Television epilepsy and pattern sensitivity. Br Med J 1977; ii: 88-90.

23 Fincham EF. Monocular diplopia. Br J Ophthalmol 1963; 47: 705-12.

24 Burian HM, Von Noorden GK. Binocular vision and ocular motility. Theory and management of strabismus. St Louis: Mosby, 1974: 260-3.

25 Bender MD. Polyopia and monocular diplopia of cerebral origin. Arch Neurol Psychiatry 1945; 54: 323-38.

26 Kinsbourne M, Warrington EK. A study of visual preservation. $J$ Neurol Neurosurg Psychiatry 1963; 26: 468-75.

27 Meadows JC. Observations of a case of monocular diplopia of cerebral origin. J Neurol Sci 1973; 18: 249-53.

28 Brindley GS, Lewin WS. The sensations produced by electrical stimulation of the visual cortex. J Physiol 1968; 196: 479-93.

29 Hubel DH, Wiesel TN. Cells sensitive to binocular depth in area 18 of the macaque monkey cortex. Nature 1970; 225: 41-2. 